\title{
Spontaneous Inspiratory Effort During Lung-Protective Ventilation
}

The reduction of tidal volume during controlled mechanical ventilation of patients with ARDS has proven to be one of the few specific interventions in critical care that can save lives. ${ }^{1}$ Indeed, there is some evidence that lungprotective ventilation strategies, including tidal volume reduction, may have a protective effect in high-risk groups and is associated with a reduction in the development of acute lung injury and pulmonary infection., ${ }^{2,3}$ Although adherence to reduced tidal volume reduction strategies remains imperfect, the median pre-randomization tidal volume in a recent study of mechanically ventilated subjects without ARDS was 7.0 (interquartile range, $6.0-8.3$ ) $\mathrm{mL} / \mathrm{kg}$ predicted body weight and was (mean $\pm \mathrm{SD}, 7.2 \pm$ $1.4 \mathrm{~mL} / \mathrm{kg}$ ) in an audit of patients who were critically ill and admitted to 16 ICUs in the United Kingdom, reflecting the evolution of ventilator practice over the past 2 decades. ${ }^{4,5}$

One of the vexing problems in implementing a low tidal volume strategy is the management of tidal volume in the presence of spontaneous inspiratory efforts. This is perhaps more relevant for "preventive" low tidal volume strategies, wherein the inclination may be to use partial ventilatory support given the lower severity of illness in a heterogenous group of patients without "ARDS." Indeed, this was a criticism of a recently published trial of low versus intermediate tidal volume ventilation for patients without ARDS; ${ }^{4}$ a high proportion of the subjects in this study were ventilated by using pressure-support ventilation, which resulted in little differentiation in tidal volume between the low and intermediate tidal volume groups, which, in turn, may have led to negative trial results. ${ }^{6}$ This may also be a problem in ARDS, wherein high respiratory drive related to hypercapnia, acidosis, hypermetabolism, systemic inflammation, pain, and anxiety may lead to vigorous respiratory effort and larger-than-prescribed tidal volume unless deep sedation is used.

A question germane to this issue is the following: Is spontaneous breathing with either large or small tidal

The author has disclosed no conflicts of interest.

Correspondence: Steven Deem MD, Swedish Medical Center, Cherry Hill Campus, $50017^{\text {th }}$ Ave, Seattle, WA 98122.E-mail: steven.deem@swedish.org.

DOI: $10.4187 /$ respcare.07198 volumes harmful in ARDS (or pre-ARDS)? Experimental evidence from the 1980s found that pharmacologically induced spontaneous hyperventilation in sheep for 12-24 h resulted in acute lung injury. ${ }^{7}$ In a more recent study, strong spontaneous ventilation induced by doxapram in experimental acute lung injury was associated

See the Original Study on Page 890

with worse histologic injury only in animals ventilated with "moderate" tidal volumes $(7-9 \mathrm{~mL} / \mathrm{kg}$ ) compared with low tidal volume ventilation $(6 \mathrm{~mL} / \mathrm{kg}) .{ }^{8}$ In contrast, results of other experimental and clinical studies suggest a protective effect of spontaneous ventilation in acute lung injury. ${ }^{9}$ In particular, unrestricted (and unsupported) spontaneous ventilation during airway pressure release ventilation has been advocated as potentially beneficial for patients with ARDS. ${ }^{10}$ Spontaneous breathing during airway pressure release ventilation improves gas exchange and reduces cyclic alveolar collapse in experimental acute lung injury, which may reduce ventilator-associated lung injury. ${ }^{11}$ Clinically, this approach has been found to result in reduced duration of mechanical ventilation and length of intensive care stay in comparison with pressure control ventilation. ${ }^{12}$ Thus, the effect of spontaneous ventilation on outcomes during the management of ARDS or in patients who are at risk for ARDS remains uncertain at this time, and additional clinical studies are needed.

Several factors associated with ventilator mode and settings have been identified as potential modifiers of tidal volume. In the audit of United Kingdom ICU ventilation practices, the use of pressure control ventilation resulted in higher average tidal volumes than volume control ventilation (mean $\pm \mathrm{SD}, 7.9 \pm 1.8 \mathrm{~mL} / \mathrm{kg}$ vs $7.0 \pm 1.2 \mathrm{~mL} / \mathrm{kg}$ ). ${ }^{5}$ Likewise, Needham et al ${ }^{13}$ noted slightly larger tidal volumes in association with the use of pressure control versus the use of pressure regulated volume control, and a higher percentage of time spent with excessively large tidal volumes (19\% vs 9\%). However, these studies do not directly address the issue of spontaneous inspiratory efforts, and the factors that lead to exuberant spontaneous ventilatory efforts by patients who are critically ill are mainly speculative. 


\section{EDITORIALS}

In the current issue of RespiRATORy CARE, Koide et al ${ }^{14}$ reported an attempt to identify factors associated with low tidal volume ventilation in a consecutive series of mechanically ventilated subjects who were admitted to a medical and surgical ICU of a tertiary hospital in Osaka, Japan. Their analysis was restricted to patients with a $\mathrm{P}_{\mathrm{aO}} / \mathrm{F}_{\mathrm{IO}_{2}}<300 \mathrm{~mm} \mathrm{Hg}$ and to those with spontaneous inspiratory efforts. Low tidal volume was defined as $<8 \mathrm{~mL} / \mathrm{kg}$ (predicted body weight). A unique aspect of their study was that they investigated acidbase status associations with tidal volume by using the Stewart model. In particular, the associations among strong ion difference and total nonvolatile weak acids and tidal volume were explored, in addition to associations with a variety of other physiologic and clinical variables. The authors found that a high strong ion difference combined with a low total nonvolatile weak acids, which indicated a tendency toward metabolic alkalosis, was associated with low tidal volume. Paradoxically, they also found that the administration of opioids was associated with a higher tidal volume, a finding that is difficult to explain due to the retrospective nature of the study; it may be that opioids were preferentially administered to subjects with vigorous inspiratory efforts rather than being causative of higher tidal volumes.

It is not particularly surprising that metabolic alkalosis is associated with lower spontaneous ventilatory effort, and Koide et al ${ }^{14}$ reasonably suggest that manipulation of buffering might be one way to promote low tidal volume ventilation. That said, the individual correlations among a strong ion difference, total nonvolatile weak acids, and tidal volume in the current study were extremely weak, each accounting for $<1 \%$ of the variability in tidal volume. These findings suggest that there were other more important and as yet undefined factors that affected subjects' spontaneous inspiratory efforts. Related to this was a major limitation of the current study in that the authors did not provide a convincing argument that the difference in tidal volume between the low and high groups was due to spontaneous inspiratory effort; given that all the subjects seemed to be ventilated by using pressure-regulated modes, differences in respiratory mechanics (compliance and resistance) could account for much of the difference in tidal volume.

The authors are to be congratulated for their efforts to identify factors associated with the achievement of low tidal volume ventilation in patients on mechanical ventilation and with spontaneous inspiratory efforts, but more research is needed to guide respiratory therapists and clinicians in their quest to optimize management of these patients. Fundamental questions remain: Are spontaneous inspiratory efforts detrimental or beneficial in acute lung injury, and can these efforts be modulated to the benefit of patients?

Steven Deem

Swedish Medical Center

Seattle, Washington

\section{REFERENCES}

1. Petrucci N, De Feo C. Lung protective ventilation strategy for the acute respiratory distress syndrome. Cochrane Database Syst Rev 2013(2):CD003844.

2. Sutherasan Y, Vargas M, Pelosi P. Protective mechanical ventilation in the non-injured lung: review and meta-analysis. Crit Care 2014; 18(2):211.

3. Serpa Neto A, Cardoso SO, Manetta JA, Pereira VG, Esposito DC, Pasqualucci Mde O, et al. Association between use of lung-protective ventilation with lower tidal volumes and clinical outcomes among patients without acute respiratory distress syndrome: a meta-analysis. JAMA 2012;308(16):1651-1659.

4. Writing Group for the PI, Simonis FD, Serpa Neto A, Binnekade JM, Braber A, Bruin KCM, et al. Effect of a low vs intermediate tidal volume strategy on ventilator-free days in intensive care unit patients without ARDS: a randomized clinical trial. JAMA 2018;320(18):18721880.

5. Newell CP, Martin MJ, Richardson N, Bourdeaux CP. Protective mechanical ventilation in United Kingdom critical care units: a multicentre audit. J Intensive Care Soc 2017;18(2):106-112.

6. Slagt C, van Eijk L. Tidal volume ventilation strategy in ICU patients without ARDS. JAMA 2019;321(13):1311-1312.

7. Mascheroni D, Kolobow T, Fumagalli R, Moretti MP, Chen V, Buckhold D. Acute respiratory failure following pharmacologically induced hyperventilation: an experimental animal study. Intensive Care Med 1988;15(1):8-14.

8. Yoshida T, Uchiyama A, Matsuura N, Mashimo T, Fujino Y. Spontaneous breathing during lung-protective ventilation in an experimental acute lung injury model: high transpulmonary pressure associated with strong spontaneous breathing effort may worsen lung injury. Crit Care Med 2012;40(5):1578-1585.

9. Gama de Abreu M, Guldner A, Pelosi P. Spontaneous breathing activity in acute lung injury and acute respiratory distress syndrome. Curr Opin Anaesthesiol 2012;25(2):148-155.

10. Brander L, Slutsky AS. Assisted spontaneous breathing during early acute lung injury. Crit Care 2006;10(1):102.

11. Wrigge H, Zinserling J, Neumann P, Muders T, Magnusson A, Putensen $\mathrm{C}$, et al. Spontaneous breathing with airway pressure release ventilation favors ventilation in dependent lung regions and counters cyclic alveolar collapse in oleic-acid-induced lung injury: a randomized controlled computed tomography trial. Crit Care 2005;9(6):R780-R789.

12. Putensen C, Zech S, Wrigge H, Zinserling J, Stuber F, Von Spiegel $\mathrm{T}$, et al. Long-term effects of spontaneous breathing during ventilatory support in patients with acute lung injury. Am J Respir Crit Care Med 2001;164(1):43-49.

13. Needham M, Smith R, Bauchmuller K. Pressure-regulated volume control ventilation as a means of improving lung-protective ventilation. J Intensive Care Soc 2019;20(1):NP6-NP7.

14. Koide M, Uchiyama A, Yamashita T, Yoshida T, Fujino Y. Attaining low tidal volume ventilation during patient-triggered ventilation in sedated subjects. Respir Care 2019;64(8):890-898. 